\title{
Experimental modelling of critical damage obtained in Al-Mg and Al-Mn alloys for both annealed state and previously deformed by ECAP
}

\author{
R. Luri, J.P. Fuertes, C.J. Luis, D. Salcedo, I. Puertas and J. León
}

Mechanical, Energetics and Materials Engineering Department

Public University of Navarre

Campus de Arrosadía, s/n

31006 Pamplona (Spain)

Corresponding author's e-mail: inaki.puerta@unavarra.es

\begin{abstract}
Assessing the damage produced in plastic deformation processes permits the optimum manner to shape a material that could avoid any cracks appearing. In this present research work, the absolute critical damage in the following aluminium alloys: AA5754, AA5083 and AA3103 is to be determined. In order to do this, compression tests between plane-shape dies will be performed for the above-mentioned alloys at a temperature range which varies from $25{ }^{\circ} \mathrm{C}$ to 300 ${ }^{\circ} \mathrm{C}$ and using Cockroft-Latham's prediction model. Furthermore, the results obtained by finite volume simulations will be compared with those obtained by experimental tests with isothermal upsetting. Given that in these last few years there has been a growing interest in obtaining mechanical components from submicrometric and/or nanometric structure materials which have been previously-processed by severe plastic deformation (SPD), this present research work deals with the determination of absolute critical damage for the above-mentioned alloys once they have been ECAP (Equal Channel Angular Pressing) processed. This is considered to be of interest since it could allow the prediction of optimal processing conditions in advance.
\end{abstract}

Keywords: Damage, ECAP, modelling

\section{Introduction}

A large number of damage models have been examined over the past few years in order to be able to predict damage growth for different types of industrial and mechanical applications [1]. One of the most widely-used damage 
models is Lemaitre's, who also has diverse formulations which deal with anisotropic damage such as that shown by Lemaitre et al. [2]. A strong anisotropic fracture behaviour in forged AA6061 is reported by Shen et al. [3], where this anisotropic damage evolution is mainly due to the anisotropic distribution of intergranular precipitates. These researchers use a GursonTvergaard-Needleman (GTN) model as a constitutive damage model in order to perform the finite element simulations of notched specimens.

It is very important for fracture criteria to assess their accuracy in predicting and in quantifying the fracture initiation. Accordingly, Gouveia et al. [4] study the validity of four ductile fracture criteria (Freudenthal's, Cockcroft and Latham's, Brozzo's and Oyane's) by means of performing several workability experimental tests with ring, cylindrical, tapered and flanged upset samples. One of the most relevant conclusions of this study is that the most advantageous workability criterion to be implemented in available finite element software is Oyane's.

Moreover, the assessment of the damage imparted to the material is extremely important. In research works by Puertas et al. [5] and by Luis Pérez et al. [6], damage values for ECAP-processed and isothermally forged parts manufactured from AA1050 and AA5083, respectively, are calculated by FEM simulations using the Cockcroft-Latham's model [7].

There has been a great deal of recent research into the methodologies for the failure analysis of composite laminates, constitutive modelling, failure criteria and damage evolution laws [8]. Nevertheless, this present research work is focused on aluminium alloys, such as AA5754, AA5083 and AA3103. With respect to the damage evolution of ECAP-processed AA5083, Luri et al. [9] analyse the influence of the ECAP die geometry on the damage imparted to the so-processed parts. One of the most important conclusions from these authors is that the fillet radii of the intersection between both die channels and its intersection angle play an important role in the damage. The results of this research work are in line with those obtained by Comaneci et al. [10], where the damage evolution of ECAP-processed AA5052 is studied. According to these researchers, cracking may be reduced or even eliminated by modifying the inner radius of the ECAP die.

Figueiredo et al. [11] also carry out a study on the damage evolution of an aluminium alloy (Al-1.3\% Fe-0.6\% Mg-0.1\% Si) under two different conditions: 
after annealing and after ECAP to produce a material with a near perfect-plastic behaviour. The analysis made by these researchers show that cracks may form in the interior of the material with strain hardening behaviour, the propagation of these cracks leading to billet segmentation. On the other hand, in the case of near perfect-plastic behaviour, the cracks are superficial and reasonably stable. Katani et al. [12] develop a simulation method in order to predict the effect of microstructural morphology both on the mechanical properties and on the failure mechanism of a titanium alloy (Ti-6Al-4V). The simulated mechanical properties and the damage evolution in terms of micro-voids formation are compared with the experimental results. The results show that the failure pattern is not severely deviated from the classical ductile failure.

Another notable research work is that by Costa Mattos et al. [13]. These researchers propose a simple continuum damage model, in order to be able to describe tensile tests for AZ31 Mg alloy sheets. Their idea is to use the proposed model in order to obtain information about the superplastic behaviour of the previously-mentioned $\mathrm{Mg}$ alloy from a minimum set of laboratory tests. It is shown that there is very good agreement between experimental results and those predicted by the model, for different strain rate values.

The measurement and the determination of damage is a very interesting aspect to be taken into account. Pepel et al. [14] compares the three most commonlydiscussed damage detection methods, which are as follows: the method of the elastic modulus, the method of maximum stress and the method of plastic strain energy. These methods are applied to two different types of steels: one with a high yield strength value (Armox 500T) and the other with a low yield strength value (42CrMo4). Based on the materials analysed, the damage determination by plastic strain energy is satisfactory for both materials but on the other hand, the elastic modulus method, which is the most frequently applied, turns out to be more appropriate for low-yield strength materials than for high-yield strength materials.

Shang [15] measures the fatigue damage for spot-welded joints using the natural frequency as it is thought that fatigue damage may be quantitatively described by the relative change of the natural frequency during the fatigue process. To this end, a new damage variable is proposed based on the natural frequency non-linear behaviour with the cycle ratio in order to satisfactorily 
develop a fatigue damage evolution equation both for describing the damage process and for predicting the fatigue life of spot-welded joints.

In order to model absolute damage (D) for AA5083, AA5754 and AA3103, this research work employs Cockroft-Latham's damage model (Eq. (1)).

$D=\int \frac{\sigma_{\max }}{\bar{\sigma}} d \varepsilon$

Where $\sigma_{\max }$ is the maximum principal stress, $\bar{\sigma}$ is the equivalent stress and $\varepsilon$ is the plastic deformation.

Absolute damage will increase until it reaches the value where cracks appear. This damage value is known as critical absolute damage ( $\left.D_{\text {crit }}\right)$, which allows crack initiation to be predicted. Therefore, in a part which is being forged, if the absolute damage value (D) is lower than the critical absolute damage value ( $D_{\text {crit }}$ ), there will be no cracks. If the absolute damage (D) is compared with the critical absolute damage ( $D_{\text {crit }}$ ), the relative damage value ( $\left.D_{\text {rel }}\right)$ may be defined, as is shown in Eq. 2. Relative damage value (Drel) varies between 0 and 1. When relative damage value (Drel) reaches 1 , cracks appear [2].

$D_{\text {rel }}=\frac{D_{\text {absolute imparted }}}{D_{\text {crit }}}$

Nevertheless, in order to calculate the relative damage value $\left(D_{\text {rell }}\right)$, the critical absolute damage ( $D_{\text {crit }}$ ), which only depends on the material, has to be determined as shown by Lemaitre in [2].

This present research work deals with the determination of critical damage as a function of strain and process temperature. In order to do this, a new specimen is designed for the damage determination and isothermal compressions are carried out with a hydraulic press. Moreover, a comparison is made between the experimental tests and the results obtained from finite volume simulations.

\section{Set-up of the experimentation}

This present section outlines both the design of a new specimen for the analysis of the absolute critical damage and the measurement of the mechanical properties for the AA5754, AA5083 and AA3103 aluminium alloys.

\subsection{Design of the specimen for absolute critical damage to be analysed}

The geometry for the specimen designed in this research work takes as a starting point the different geometries existing in the bibliography [4], modifying one of them in order to be capable of predicting damage in a more adequate 
form and so that cracks appear on the outer surface when carrying out compressions for the damage value to be determined.

The most important advantage of this specimen in relation to those shown in [4] is that the maximum damage is achieved in a reduced zone from the central and outer part of the specimen. This makes the detection of cracks easier. From the tapered specimen, some modifications have been introduced in order to obtain a new specimen which fulfills the previously-mentioned conditions. The differences lie on the one hand, in the addition of fillet radii for all the edges and, on the other hand, in a slight increase in the length of the specimen ( $3 \mathrm{~mm})$, as may be observed in Figure 2. Both design modifications lead to the experimental fact that the highest damage value is always achieved at the previously-mentioned central zone, regardless of the final compression height.

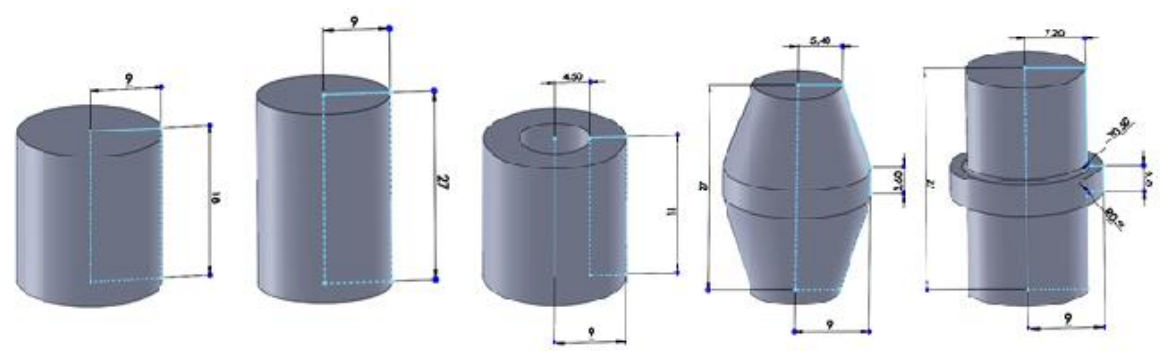

Figure 1. Initial geometries found in [4]

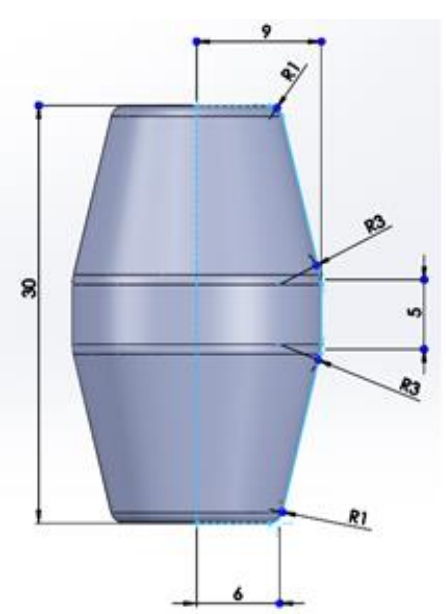

(a)

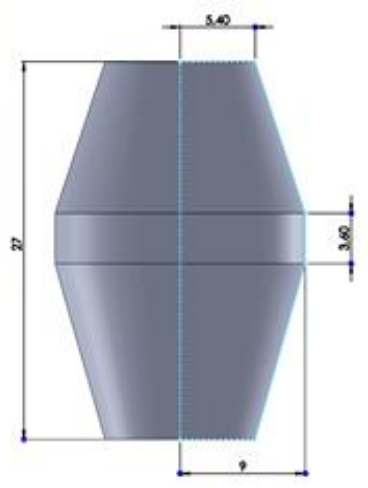

(b)

Figure 2. Comparison between: (a) the specimen proposed and (b) the specimen from [4]

Figure 3 shows the final specimen to be used in this research work based on the specimen from Figure 2(a) once it has been machined. 


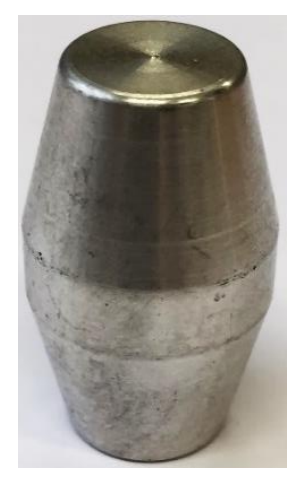

Figure 3. Experimental specimen proposed in this study

\subsection{Measurement of mechanical properties for the aluminium alloys under consideration}

The next step consists in determining the mechanical properties of the starting material. An AA5754 aluminium alloy is selected. The N0 state corresponds with the material in an annealed state. The N2 state means that the material has been previously ECAP-processed twice with route $C$ whereas the $N 4$ state corresponds with four ECAP passages following route $\mathrm{Bc}$ [10]. The N2 + flash heat treatment initial state means that the $\mathrm{N} 2$ state material is subjected to a heat treatment up to $300{ }^{\circ} \mathrm{C}$ with a heating slope of $12{ }^{\circ} \mathrm{C} / \mathrm{min}$ and a fast cooling down to room temperature. This is performed because earlier studies by these present authors on the manufacturing of mechanical components by forging from nanostructured materials have shown that cracks appear if the starting material is in N2 state, due to the high accumulated strain value [16]. Therefore, when the flash treatment is carried out, components are forged with no cracks and, in addition, the material does not undergo a significant loss of mechanical properties in relation to N2. For this reason, the use of a starting material in N2 state + flash treatment is considered to be of interest in this present research work.

In order to obtain the flow curves for the materials under consideration in this present study, isothermal compression tests between plane-shape dies have been performed on cylindrical billets with a height of $16 \mathrm{~mm}$ and a diameter of 8 $\mathrm{mm}$, as can be observed in Figure 4. The stress-strain curves obtained are shown in Figure 5. The temperature values selected are as follows: $25^{\circ} \mathrm{C}, 100$ $\stackrel{\circ}{ } \mathrm{C}, 150 \stackrel{\circ}{\circ}, 200 \stackrel{\circ}{ } \mathrm{C}, 250 \stackrel{\circ}{ } \mathrm{C}$ and $300 \stackrel{\circ}{ } \mathrm{C}$. 


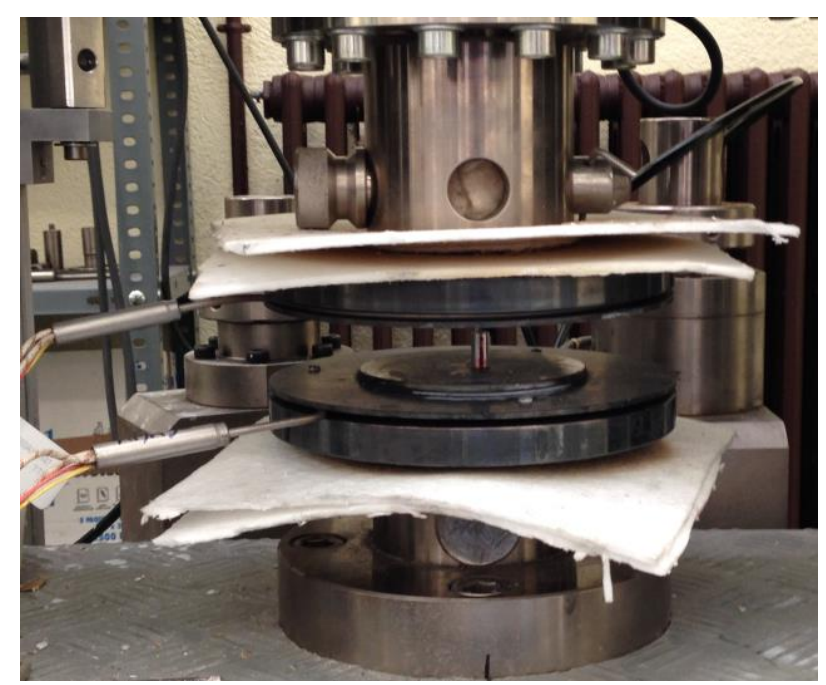

Figure 4. Set-up of die heating device for isothermal upset forging

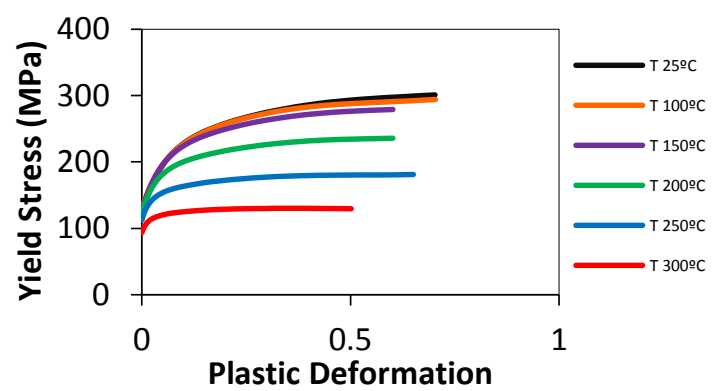

(a). Flow curves for previously annealed AA5754

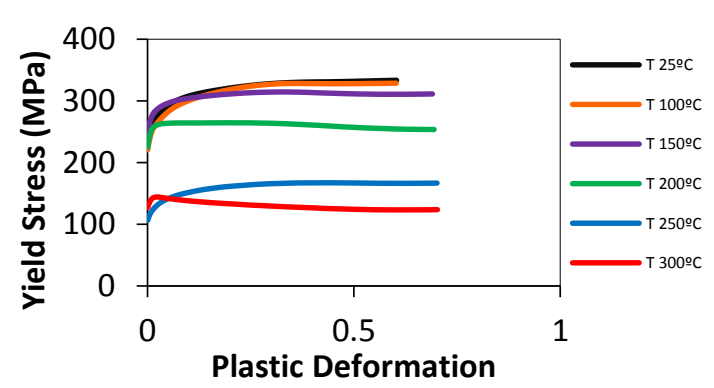

(c). Flow curves for AA5754 previously ECAPprocessed up to two passages and with flash heat treatment (N2+flash)

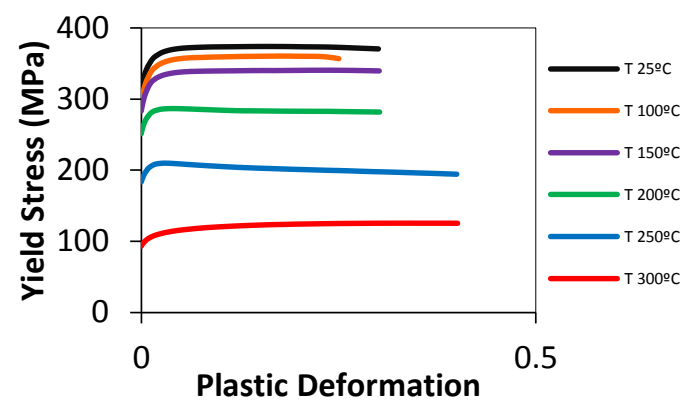

(b). Flow curves for AA5754 previously ECAP-processed up to two passages (N2)

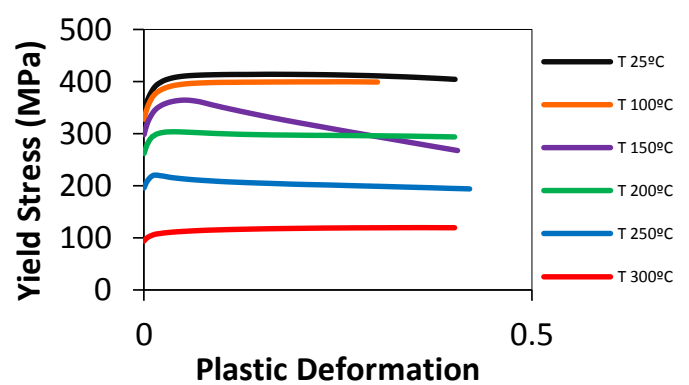

(d). Flow curves for AA5754 previously ECAP-processed up to four passages (N4)

Figure 5. Flow curves for AA5754

As can be observed in Figure 5 (c) and Figure 5 (d), there are two flow curves (for $\mathrm{T}=300{ }^{\circ} \mathrm{C}$ and $\mathrm{T}=150{ }^{\circ} \mathrm{C}$, respectively) each of which show a different 
behaviour. This is due to the dynamic recrystallization which takes place during the compression test at those temperatures for each aluminium alloy.

Figure 6 shows optical micrographs for each of the starting materials, where it may be observed that the lowest grain size is found in N2 (Figure 6.b) as opposed to N0 (Figure 6.a). Moreover, in the case of N2 + flash (Figure 6.c), the grain size is in-between and deformation bands arising from the ECAP processing may be observed.

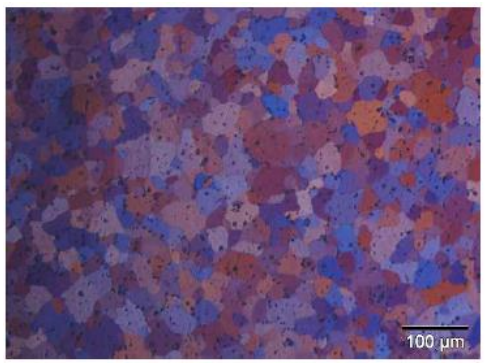

a) $\mathrm{NO}$

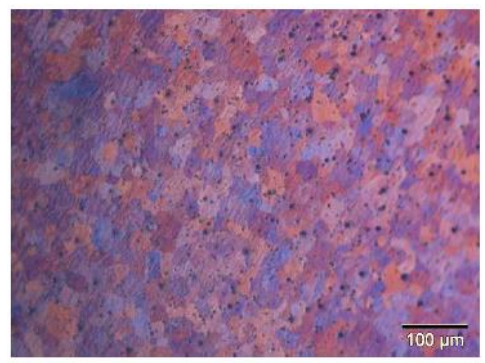

b) $\mathrm{N} 2$

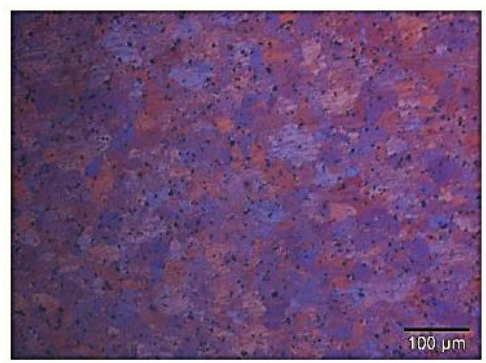

c) $\mathrm{N} 2+$ flash

Figure 6. Comparison of optical micrographs

Taking the SEM micrographs shown in Figure 7 into account, it may also be seen that the three starting states selected have a different grain size. A grain size much higher than $1 \mu \mathrm{m}$ is observed for the material in N0 state (Figure 7.a) whereas for N2 (Figure 7.b) and N2 + flash (Figure 7.c), the grain size is of a submicrometric level, with $\mathrm{N} 2$ being the smallest one.

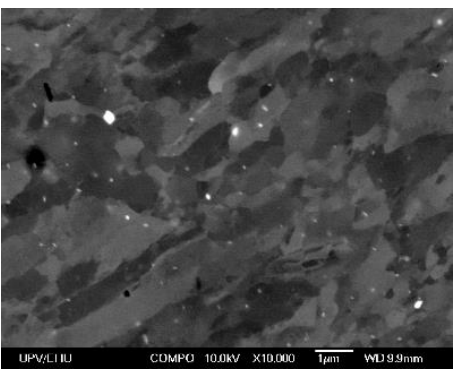

a) $\mathrm{NO}$

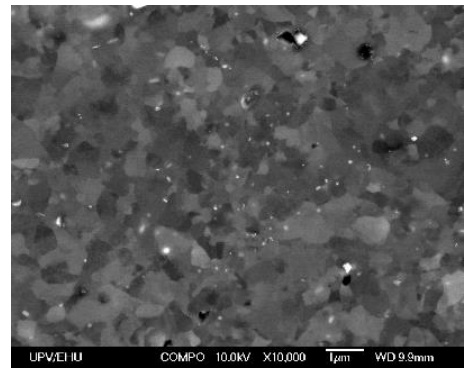

b) $\mathrm{N} 2$

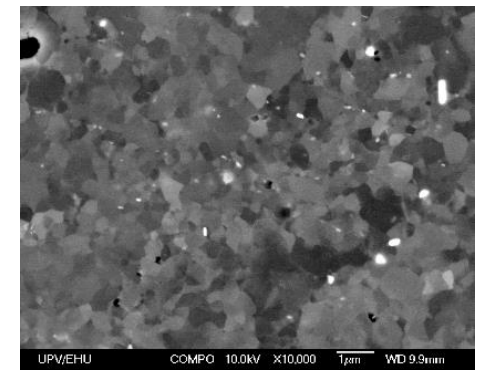

c) $\mathrm{N} 2+$ flash

Figure 7. Comparison of SEM micrographs for AA5754

Table 1 shows the microhardness measurements performed on AA5754 billets in N0, N2 and N2 + flash states in order to compare the influence of the heat treatment on the previously-nanostructured material. As can be observed, there is a drop of $20 \%$ in microhardness for $\mathrm{N} 2+$ flash in relation to N2 but the 
improvement is still around $30 \%$ in relation to N0. The microhardness measurements have been taken with a load of $300 \mathrm{~g}$ and the locations selected are the billet centre and one point at each direction of the coordinate axes.

Table 1. AA5754 Microhardness (HV) for each different starting state

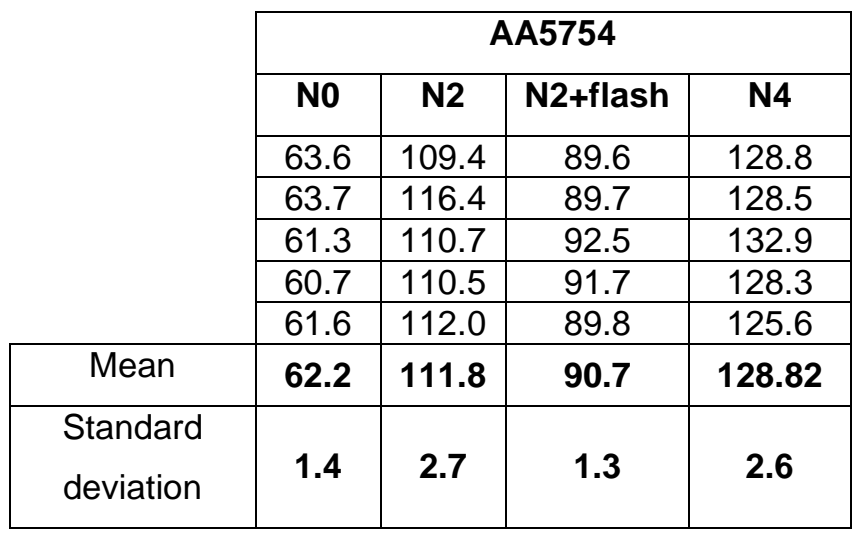

\section{FEM and experimental results}

First, it is necessary to model the geometries which are involved in the process. Figure 8 shows the final configuration for the performance of the finite volume simulations using the Simufact $12^{\mathrm{TM}}$ software and SolidWorks ${ }^{\mathrm{TM}} 2015$.

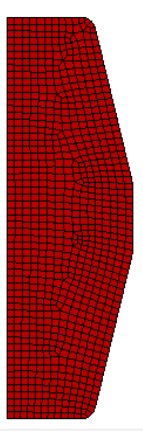

(a). Billet initial mesh

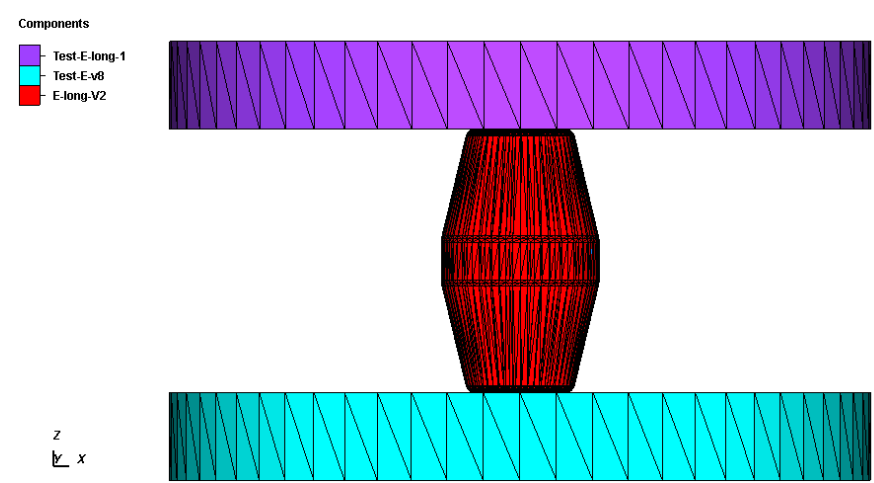

(b). Final assembly

Figure 8. CAD model for the selected damage specimen and upper and lower dies

Once modelled and imported, with the specimen geometry to be studied, the material to be used in the tests is selected. In this present study, as was previously-mentioned, AA5754 aluminium alloy was selected. For a better performance, the material flow rules are uploaded in the software for the different temperature values and for the different starting states (N0, N2, N2 + flash and N4). The yield stress behaviour (flow rule) is introduced by a 
piecewise function which takes plastic strain and temperature into account. Each compression flow curve is obtained from experimental tests. If it is necessary to carry out a compression test with a different temperature, the software adjusts the material behaviour by interpolating the curves introduced.

Once the material is characterised, the meshing process is carried out for the proposed specimen. To this end, hexahedral elements are used with an edge size of $0.5 \mathrm{~mm}$. Several re-meshing processes are programmed during the simulation process in order to avoid excessive distortion of the elements due to compression. The type of element used during the re-meshing process is the same as the one for the initial meshing. Figure 8 (a) shows the cross-section of the meshed specimen.

Subsequently, isothermal compression conditions are established. The press descent velocity is $60 \mathrm{~mm} / \mathrm{min}$ and the stroke value for the upper die depends on the specimen's final height, where its minimum value selected for this present research work is $2 \mathrm{~mm}$. Moreover, it is necessary for the software to indicate the temperature value at which compression is going to be performed. In this case, the temperature range selected is as follows: $25^{\circ} \mathrm{C}, 100 \stackrel{\circ}{\circ} \mathrm{C}, 150$ ${ }^{\circ} \mathrm{C}, 200^{\circ} \mathrm{C}, 250{ }^{\circ} \mathrm{C}$ and $300{ }^{\circ} \mathrm{C}$. These previous temperature values have been selected taking into account the real conditions for the tests to be carried out. A heat transfer coefficient (h) of $50 \mathrm{~W} / \mathrm{m}^{2} \mathrm{~K}$ has also been employed. A friction criterion of Tresca's type is chosen with an " $m$ " value of 0.3 , as is shown in previous studies from these present researchers [16].

Once the procedure followed to model the damage tests by finite volume has been commented, the process followed in order to carry out the damage experimental analysis is outlined. To this end, the attainment of the absolute critical damage is studied for the three aluminium alloys (AA5754, AA5083 and AA3103) and for the four starting states under consideration summarised in Table 2.

Table 2. Materials and starting states to be used in the experiments

\begin{tabular}{|l|c|c|c|}
\cline { 2 - 4 } \multicolumn{1}{c|}{} & AA5754 & AA5083 & AA3103 \\
\hline N0 & Yes & Yes & Yes \\
\hline N2 & Yes & Yes & Yes \\
\hline N2 + flash & Yes & No & No \\
\hline N4 & Yes & No & Yes \\
\hline
\end{tabular}


This present study consists in performing isothermal compressions between plane-shape dies on one specimen (shown in Figure 3) at different height values, until the range of final height values in which no cracks appear on the specimen surface is determined. The final height range goes from $10 \mathrm{~mm}$ to 2 $\mathrm{mm}$, where its value may vary every $0.5 \mathrm{~mm}$.

Figure 9 shows the set of dies designed to carry out this study. Five cavities may be appreciated in the bottom die, which correspond with the height values at $10 \mathrm{~mm}$ (bottom), $8 \mathrm{~mm}$ (left), $6 \mathrm{~mm}$ (upper), $4 \mathrm{~mm}$ (right) and $2 \mathrm{~mm}$ (central).

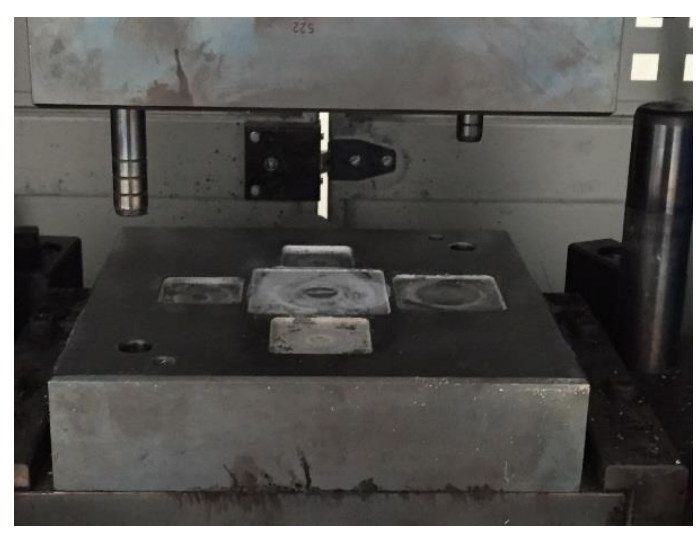

Figure 9. Set of dies employed to perform the isothermal compressions

The procedure followed for each alloy and temperature is as follows: the lowest temperature $\left(25{ }^{\circ} \mathrm{C}\right)$ is selected to start and compressions are carried out until the range of height values in which the crack is found is determined. Once this range is determined, plates of $1 \mathrm{~mm}$ and $0.5 \mathrm{~mm}$ thickness are used in order to get an interval of $0.5 \mathrm{~mm}$.

In this present section, damage results obtained are shown both in the case of the finite volume simulations and in the case of the experimental tests.

\subsection{FEM results}

This section outlines the results obtained for the finite volume simulations. As was mentioned above, on the one hand, the damage evolution is analysed as a function of the height value for the designed geometry and on the other hand, absolute critical damage values are attained for each of the previously-selected height values. 
Figure 10 (a) (at a final height of $10 \mathrm{~mm}$ ) shows that the zone where the highest damage values are found is the central zone, which is located between the fillet radii of $3 \mathrm{~mm}$, as was expected when designing the specimen proposed. This makes the crack detection easier in the specimens compressed down to that height value. Moreover, as the specimen is being compressed more and more (Figure 10 (b) to (d), the maximum damage value spreads along the outer surface. Once the minimum height value is reached (see Figure $10(\mathrm{e})$ ), the maximum damage value is located throughout the outer surface of the specimen, with this zone being where cracks appear when experimental tests are performed.

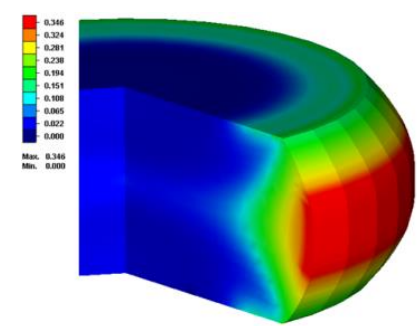

(a) Final height at $10 \mathrm{~mm}$

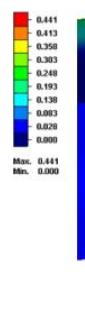

(b) Final height at $8 \mathrm{~mm}$

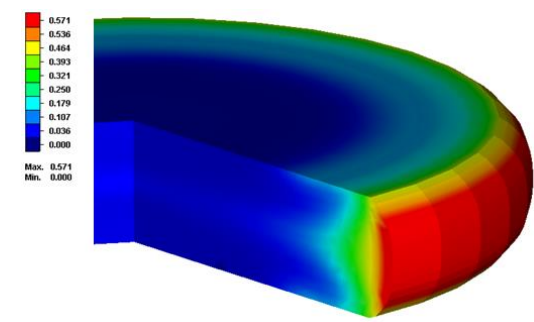

(c) Final height at $6 \mathrm{~mm}$

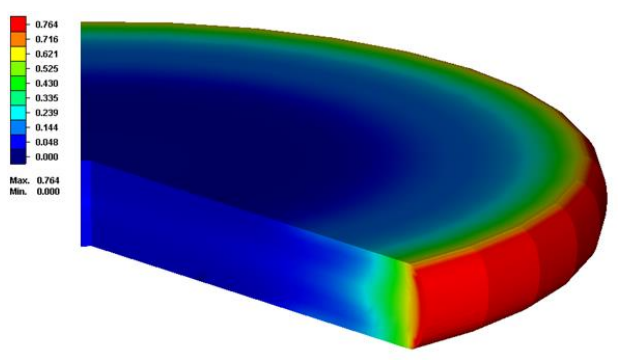

(d) Final height at $4 \mathrm{~mm}$

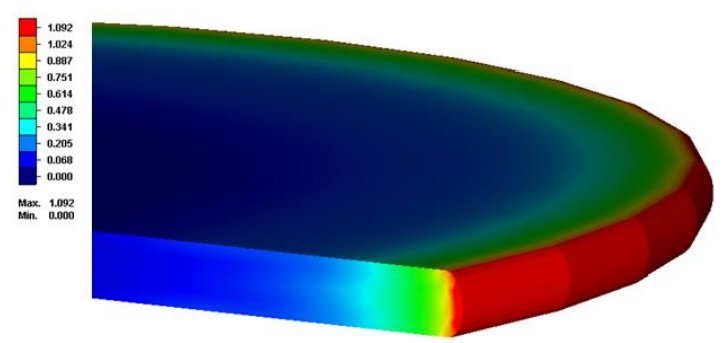

(e) Final height at $2 \mathrm{~mm}$

Figure 10. Damage distribution at different specimen height values for $T=25^{\circ} \mathrm{C}$

As well as evaluating the specimen damage distribution for each compression height value, damage value evolution is studied during the process at a specific point from the outer surface. The aim is to be able to obtain the damage value at each height value, where this will be utilised in order to quantify the maximum damage value at each height value for the experimental tests. The damage value obtained at the height from which cracks start to appear is the absolute critical damage. Figure 11 shows the curve obtained when damage attained at each compression instant is related. 


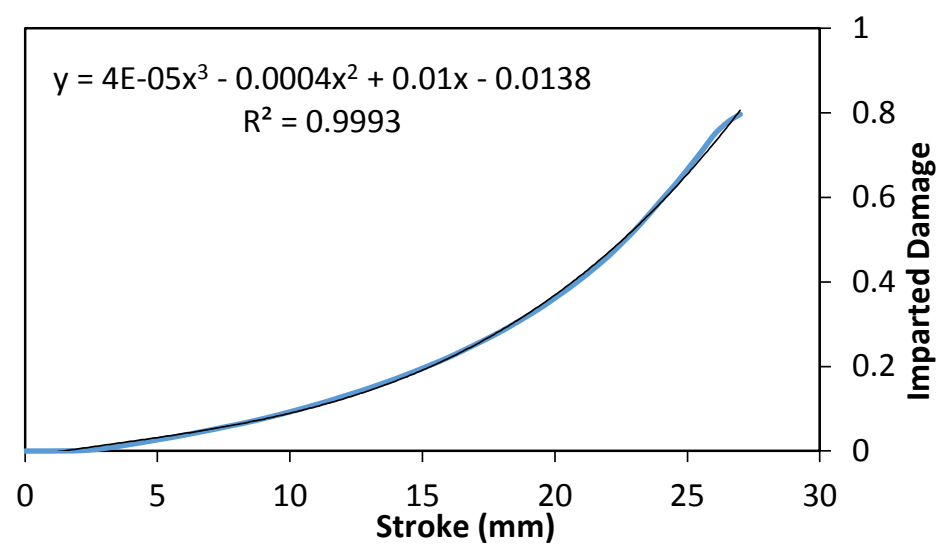

Figure 11. Damage evolution during compression $\left(R^{2}=99.93 \%\right.$; adjusted $\left.R^{2}=99.92 \%\right)$

\subsection{Experimental results}

Once these results from the finite volume simulations have been shown, the results obtained in the experimental tests are to be outlined. The isothermal compressions are carried out in the hydraulic press shown in Figure 12.

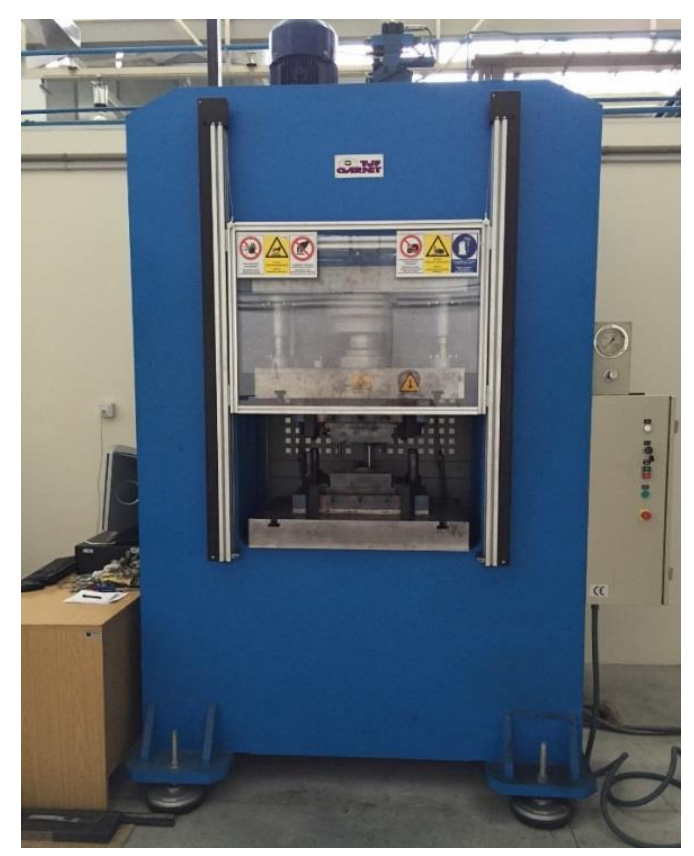

Figure 12. 300 t hydraulic press

As was mentioned earlier, a study of three aluminium alloys (AA5754, AA5083 and AA3103) is made for different starting states (N0, N2, N2 + flash and N4) and at different temperature values $\left(25^{\circ} \mathrm{C}, 100^{\circ} \mathrm{C}, 150 \stackrel{\circ}{\circ} \mathrm{C}, 200^{\circ} \mathrm{C}, 250{ }^{\circ} \mathrm{C}\right.$ and $300^{\circ} \mathrm{C}$ ). Figure 13 shows the results for the compressions tests carried out on AA5754 in N2 state at $25 \stackrel{\circ}{\circ}$, following the above-mentioned procedure. 


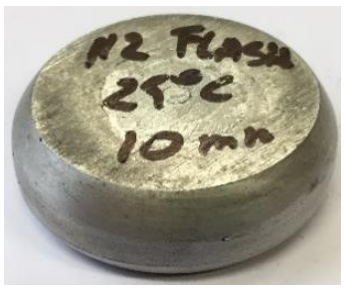

(a). $H_{\text {final }}=10 \mathrm{~mm}$

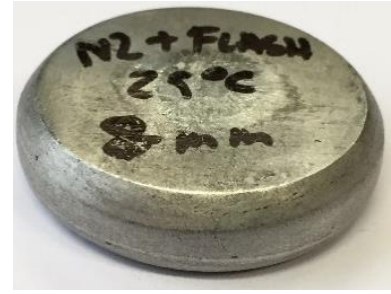

(b). $H_{\text {final }}=8 \mathrm{~mm}$

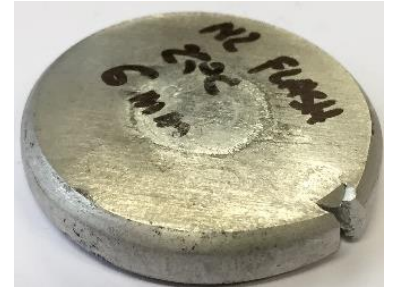

(c). $H_{\text {final }}=6 \mathrm{~mm}$

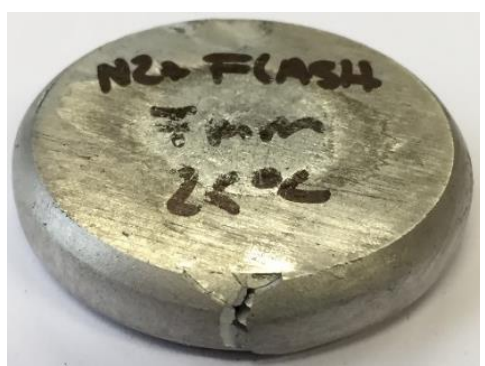

(d). $H_{\text {final }}=7 \mathrm{~mm}$

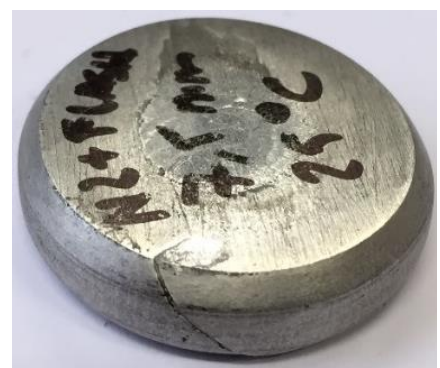

(e). $H_{\text {final }}=7.5 \mathrm{~mm}$

Figure 13. Experimental isothermal compression procedure for the N2 AA5754 at $25^{\circ} \mathrm{C}$

Figure 14 (a) and (b) show two compressed specimens where a crack may be observed in Figure 14 (a) as well as the typical "orange skin" formation on the surface, which usually precedes the appearance of a crack.

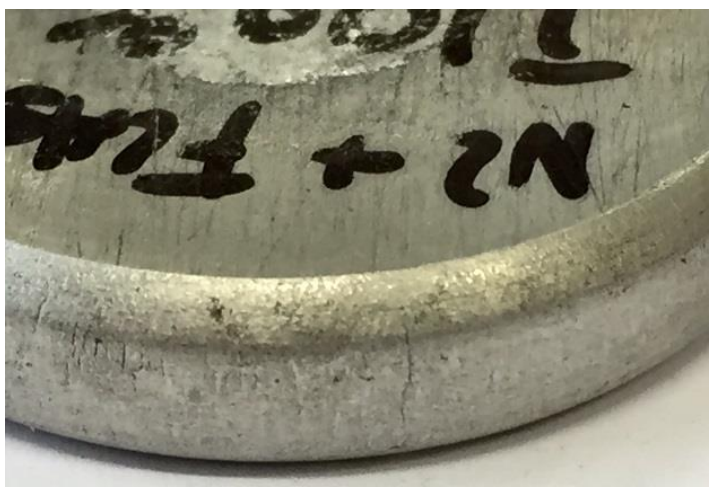

(a). Specimen with cracks (N2+flash at 100 $\left.{ }^{\circ} \mathrm{C}\right)$

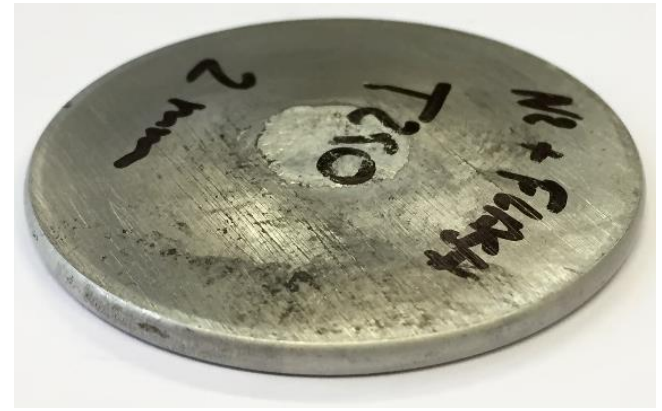

(b). Specimen with no cracks (N2+flash at $250 \stackrel{\circ}{ } \mathrm{C})$

Figure 14. Specimens with and without cracks

\section{Discussion of results}

This present section outlines the results obtained in the experimental tests for each of the three aluminium alloys under consideration in accordance with the procedure shown in earlier sections. 
Table 3 shows the critical compression height $\left(\mathrm{H}_{\text {crit }}\right)$ and the absolute critical damage ( $\left.D_{\text {crit }}\right)$ for each material and temperature. These values are calculated from Figure 11.

Table 3. Absolute critical damage results for AA5754

\begin{tabular}{|c|c|c|c|c|c|c|c|c|c|c|c|c|}
\hline \multirow[b]{2}{*}{ AA5754 } & \multicolumn{2}{|c|}{$25^{\circ} \mathrm{C}$} & \multicolumn{2}{|c|}{$100 \stackrel{\circ}{C}$} & \multicolumn{2}{|c|}{$150^{\circ} \mathrm{C}$} & \multicolumn{2}{|c|}{$200 \stackrel{\circ}{\circ}$} & \multicolumn{2}{|c|}{$250^{\circ} \mathrm{C}$} & \multicolumn{2}{|c|}{$300^{\circ} \mathrm{C}$} \\
\hline & $\begin{array}{l}\mathrm{H}_{\text {crit }} \\
(\mathrm{mm})\end{array}$ & $D_{\text {crit }}$ & $\begin{array}{l}\mathrm{H}_{\text {crit }} \\
(\mathrm{mm})\end{array}$ & $D_{\text {crit }}$ & $\begin{array}{l}\mathrm{H}_{\text {crit }} \\
(\mathrm{mm})\end{array}$ & $D_{\text {crit }}$ & $\begin{array}{l}\mathrm{H}_{\text {crit }} \\
(\mathrm{mm})\end{array}$ & $D_{\text {crit }}$ & $\begin{array}{l}H_{\text {crit }} \\
(\mathrm{mm})\end{array}$ & $D_{\text {crit }}$ & $\begin{array}{c}H_{\text {crit }} \\
(\mathrm{mm})\end{array}$ & $D_{\text {crit }}$ \\
\hline No & 4.65 & 0.613 & 4.45 & 0.628 & 3.59 & 0.69 & 2 & 0.802 & - & - & - & - \\
\hline N2 & 10.24 & 0.257 & 10.23 & 0.258 & 5.97 & 0.52 & 4.49 & 0.625 & 3.62 & 0.688 & 3.06 & 0.728 \\
\hline N2+flash & 7.50 & 0.419 & 7.50 & 0.419 & 5.00 & 0.588 & 2 & 0.802 & - & - & - & - \\
\hline N4 & 10.24 & 0.257 & 10.24 & 0.257 & 5.51 & 0.552 & 4.53 & 0.622 & 3.23 & 0.716 & 3.08 & 0.727 \\
\hline
\end{tabular}

Compression tests are performed at different temperatures $(25 \stackrel{\circ}{\circ}, 100 \stackrel{\circ}{\circ}, 150$ ${ }^{\circ} \mathrm{C}, 200{ }^{\circ} \mathrm{C}, 250{ }^{\circ} \mathrm{C}$ and $300{ }^{\circ} \mathrm{C}$ ) for N0, N2, N2+flash and N4. For each test temperature, specimens are forged down to different final heights (which range from $10 \mathrm{~mm}$ to $2 \mathrm{~mm}$ every $0.5 \mathrm{~mm}$ ). For example, it may be observed that for the No material at $300 \stackrel{\circ}{\circ}$ and $250 \stackrel{\circ}{\circ}$, none of the billets presents cracks. Compression tests carried out at $200^{\circ} \mathrm{C}$ for N0 material show cracks only in the billet with $2 \mathrm{~mm}$ final height. In the tests at $150^{\circ} \mathrm{C}$, all the specimens with height values lower than $3.5 \mathrm{~mm}$ present cracks, whereas all the height values higher than $4 \mathrm{~mm}$ do not present cracks. In the compression tests at $25^{\circ} \mathrm{C}$ and $100{ }^{\circ} \mathrm{C}$, billets with height values lower than $4.5 \mathrm{~mm}$ have cracks.

This shows that the higher the compression is, the higher the imparted damage is. Moreover, for a specific material and a specific compression test temperature, the billet with the lowest height value without cracks presents the maximum damage value that the billet may undergo. This final compression height value and its corresponding imparted damage are called critical compression height $\left(\mathrm{H}_{\text {crit }}\right)$ and absolute critical damage ( $\left.\mathrm{D}_{\text {crit }}\right)$, respectively.

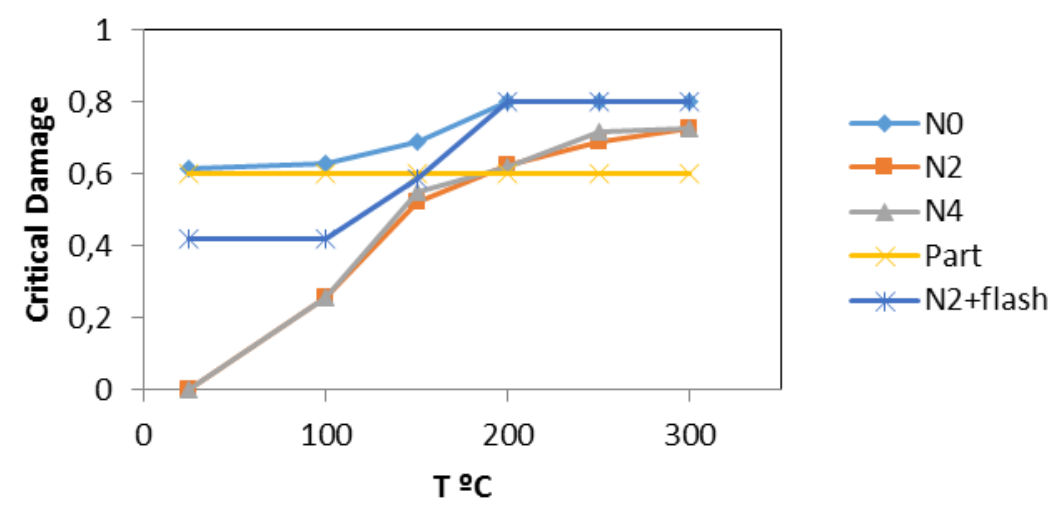


Figure 15. Absolute critical damage evolution for AA5754 as a function of temperature

Figure 15 shows the absolute critical damage evolution for AA5754 as a function of height, where it may be observed that a practically similar behaviour exists for the nanostructured starting material specimens with no heat treatments (N2 and N4). On the contrary, the annealed state material is the one with the highest absolute critical damage values at lower temperature values since this material does not present any previous hardening by ECAP. In order to obtain the most suitable forging temperature for this mechanical part, a yellow curve has also been added to represent the damage value obtained from the connecting rod FEM results.

If experimental results are compared with the damage value obtained for a connecting rod simulated by finite volume modelling (see Figure $16(\mathrm{a})$ ), it is observed that in order to carry out the forging process with no cracks for N2 and $\mathrm{N} 4$, it is necessary to increase the forging temperature above $200^{\circ} \mathrm{C}$. The same part from NO material may be practically forged at room temperature and in the case of $\mathrm{N} 2$ with flash, a temperature of around $150{ }^{\circ} \mathrm{C}$ or higher is needed.

Figure 16 (b) shows the preform and the final connecting rod forged at $200 \stackrel{\circ}{\circ}$ from N2 AA5754 material, which corroborates the results obtained by finite volume simulations. Figure 16 (d) shows another mechanical component in the form of a ring from N2 AA5083 material, in which cracks appear at $200{ }^{\circ} \mathrm{C}$ whereas there are no cracks at higher temperature values. In this case and from Table 5, it may be observed that the damage value for the ring has to be higher than 0.65 , where this number corresponds with that obtained in the finite volume simulations, which is 0.7 (see Figure 16 (c)). Furthermore, it may be observed that the zone with the highest damage value is the flash zone, where the critical damage value has been exceeded and as a consequence, it is the place where cracks first appear and subsequently, they propagate towards the inner zone, as Figure 16 (c) shows. This is confirmed in Figure 16 (d) where it may be appreciated that the cracks of the ring forged at $200{ }^{\circ} \mathrm{C}$ are located at the zones with the highest damage values obtained from the simulations. 


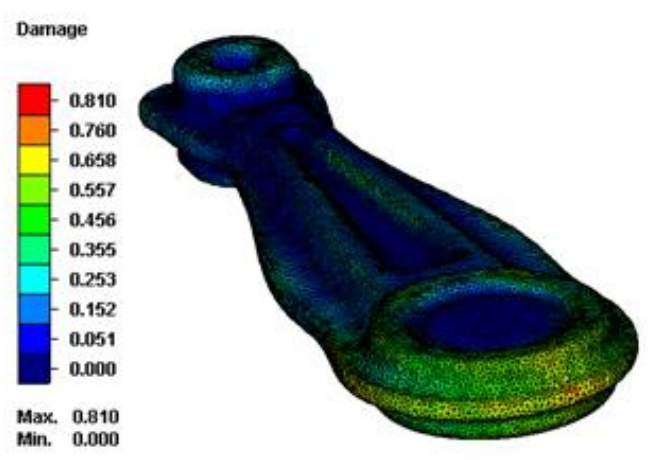

(a). Damage in connecting rod forged by FEM modelling

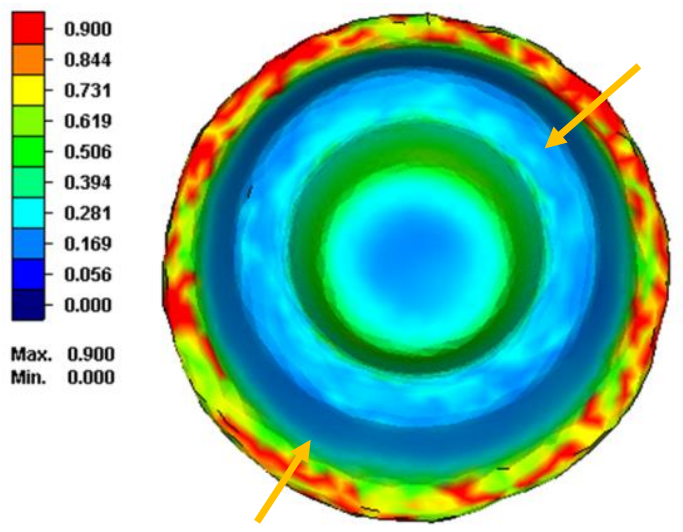

(c). Damage in a ring forged by FEM modelling showing the crack propagation

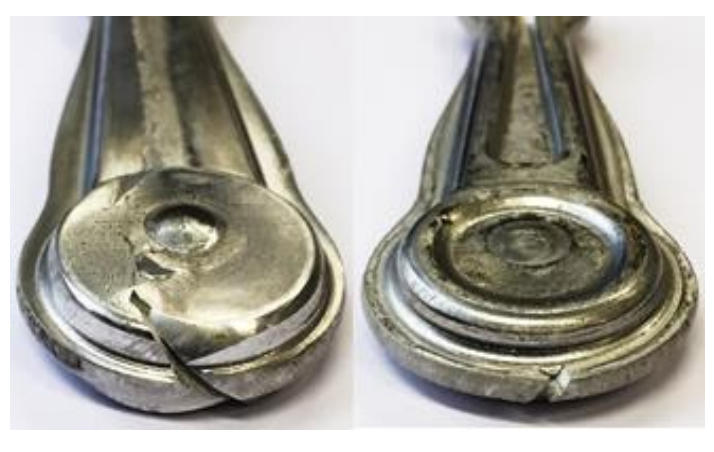

(b). Preform and connecting rod forged at $200 \stackrel{\circ}{\circ}$ from N2 AA5754

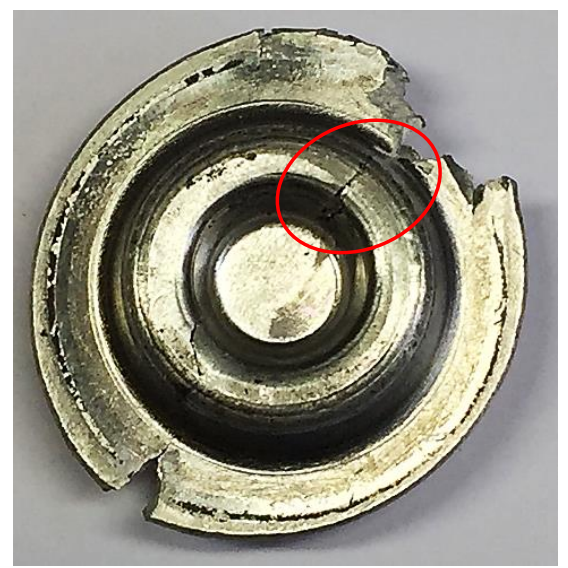

(d). Ring forged at $200 \stackrel{\circ}{\circ}$ from N2 AA5083

Figure 16. Forged parts

In order to complete this present research study, microhardness measurements are taken from the specimens where absolute critical damage is obtained, with the aim of comparing the existing difference in microhardness when the material is subjected to isothermal compression for each of the different starting states. Table 4 shows the microhardness values at different temperatures and it is found that in the case of $\mathrm{N} 2$ with flash starting state material forged at $200{ }^{\circ} \mathrm{C}$, the material microhardness is $8 \%$ higher in relation to NO starting state. However, in the case of N2 starting state, whose optimum forging temperature for the mechanical components is $250{ }^{\circ} \mathrm{C}$, the microhardness obtained is $15 \%$ lower than N2 with flash starting state material forged at $200{ }^{\circ} \mathrm{C}$. Therefore, it may be concluded that $\mathrm{N} 2$ with flash starting state shows better mechanical properties at its forging temperature rather than N2 starting state, which 
requires a higher temperature in order to achieve a mechanical component with a damage value lower than the critical one.

Table 4. Microhardness values taken from the damage specimens for each of the AA5754

\begin{tabular}{|c|c|c|c|c|c|c|c|c|c|c|c|c|}
\hline & \multicolumn{12}{|c|}{ AA5754 } \\
\hline & \multicolumn{3}{|c|}{ NO } & \multicolumn{5}{|c|}{ N2 } & \multicolumn{4}{|c|}{ N2 + Flash } \\
\hline & 100 & 150 & 200 & 100 & 150 & 200 & 250 & 300 & 100 & 150 & 200 & 250 \\
\hline & 114.6 & 105.5 & 98.5 & 118.7 & 111.5 & 108.2 & 90.2 & 83.6 & 113.7 & 106.1 & 104.1 & 92.1 \\
\hline & 113.7 & 104.2 & 95.4 & 114.6 & 114.6 & 109.0 & 94.8 & 82.6 & 113.6 & 104.8 & 106.6 & 94.3 \\
\hline & 106.8 & 105.8 & 101.2 & 125.6 & 111.4 & 113.2 & 92.3 & 82.4 & 111.6 & 105.6 & 109.7 & 92.9 \\
\hline & 116.1 & 101.1 & 101.1 & 117.0 & 111.5 & 107.6 & 93.5 & 83.6 & 113.4 & 109.0 & 107.6 & 93.8 \\
\hline & 105.7 & 102.9 & 97.4 & 123.4 & 116.1 & 114.5 & 90.1 & 82.1 & 113.8 & 112.3 & 104.2 & 94.9 \\
\hline$\overline{H V}$ & 111.4 & 103.9 & 98.7 & 119.9 & 113.0 & 110.5 & 92.2 & 82.9 & 113.2 & 107.6 & 106.4 & 93.6 \\
\hline$S_{H V}$ & 4.8 & 1.9 & 2.5 & 4.5 & 2.2 & 3.1 & 2.1 & 0.7 & 0.9 & 3.1 & 2.4 & 1.1 \\
\hline
\end{tabular}

Table 5 shows the damage results obtained for AA5083. It may be observed that up to $250^{\circ} \mathrm{C}$, it is not possible for NO state to compress a specimen down to $2 \mathrm{~mm}$ with no cracks. Furthermore, in order to obtain a specimen with no cracks for N2, it is necessary to increase isothermal compression temperature up to $300^{\circ} \mathrm{C}$.

If the results obtained from this alloy are compared with those obtained from AA5754, it may be observed that AA5083 has a higher hardening level and that is the reason why a higher process temperature is needed in order to achieve the same damage results as for AA5754.

If the values obtained in this present research study are compared with those from the forging process of a connecting rod, it is observed that it is necessary to increase the forging temperature up to $150{ }^{\circ} \mathrm{C}$ for $\mathrm{N} 0$ and up to $200{ }^{\circ} \mathrm{C}$ for $\mathrm{N} 2$.

Table 5. Absolute critical damage results for $A A 5083$

\begin{tabular}{|c|c|c|c|c|c|c|c|c|c|c|c|c|}
\hline \multirow{2}{*}{ AA5083 } & \multicolumn{2}{|c|}{$\mathbf{2 5} \mathbf{\circ}^{\circ} \mathbf{C}$} & \multicolumn{2}{c|}{$\mathbf{1 0 0}{ }^{\circ} \mathbf{C}$} & \multicolumn{2}{c|}{$\mathbf{1 5 0}{ }^{\circ} \mathbf{C}$} & \multicolumn{2}{c|}{$\mathbf{2 0 0}{ }^{\circ} \mathbf{C}$} & \multicolumn{2}{c|}{$\mathbf{2 5 0}{ }^{\circ} \mathbf{C}$} & \multicolumn{2}{c|}{$300{ }^{\circ} \mathbf{C}$} \\
\cline { 2 - 13 } & $\begin{array}{c}\mathrm{H}_{\text {crit }} \\
(\mathrm{mm})\end{array}$ & $\mathrm{D}_{\text {crit }}$ & $\begin{array}{c}\mathrm{H}_{\text {crit }} \\
(\mathrm{mm})\end{array}$ & $\mathrm{D}_{\text {crit }}$ & $\begin{array}{c}\mathrm{H}_{\text {crit }} \\
(\mathrm{mm})\end{array}$ & $\mathrm{D}_{\text {crit }}$ & $\begin{array}{c}\mathrm{H}_{\text {crit }} \\
(\mathrm{mm})\end{array}$ & $\mathrm{D}_{\text {crit }}$ & $\begin{array}{c}\mathrm{H}_{\text {crit }} \\
(\mathrm{mm})\end{array}$ & $\mathrm{D}_{\text {crit }}$ & $\begin{array}{c}\mathrm{H}_{\text {crit }} \\
(\mathrm{mm})\end{array}$ & $\mathrm{D}_{\text {crit }}$ \\
\hline $\mathrm{N} 0$ & 9.23 & 0.315 & 7.02 & 0.45 & 4.89 & 0.596 & 4.06 & 0.656 & - & - & - & - \\
\hline $\mathrm{N} 2$ & 10.32 & 0.253 & 10.29 & 0.254 & 6.96 & 0.454 & 4.67 & 0.612 & 3.41 & 0.703 & - & - \\
\hline
\end{tabular}




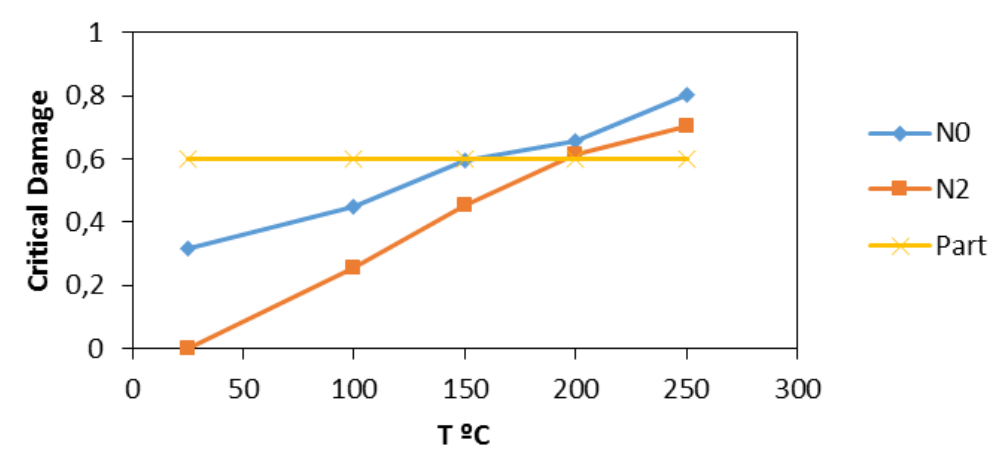

Figure 17. Absolute critical damage evolution for AA5083 as a function of temperature

It may be observed in Figure 17 that if the above-mentioned parts (Figure 16 (a)) are required to be forged, it would be necessary to increase temperature up to $200{ }^{\circ} \mathrm{C}$ in order to be able to forge them with no cracks.

Moreover, Table 6 shows the absolute critical damage results obtained in the isothermal compressions for AA3103. It may be observed that the alloy in its three starting states leads to a final specimen with no cracks at a temperature of $250{ }^{\circ} \mathrm{C}$. Nevertheless, it may be affirmed that for N0 specimens the absolute critical damage values are higher than those for N2 and N4, since a lower final height needs to be reached in order to achieve a specimen with cracks.

Table 6. Absolute critical damage results for $A A 3103$

\begin{tabular}{|c|c|c|c|c|c|c|c|c|c|c|c|c|}
\hline \multirow[b]{2}{*}{ AA3103 } & \multicolumn{2}{|c|}{$25^{\circ} \mathrm{C}$} & \multicolumn{2}{|c|}{$100 \stackrel{\circ}{\circ}$} & \multicolumn{2}{|c|}{$150^{\circ} \mathrm{C}$} & \multicolumn{2}{|c|}{$200 \stackrel{\circ}{\circ}$} & \multicolumn{2}{|c|}{$250^{\circ} \mathrm{C}$} & \multicolumn{2}{|c|}{$300 \stackrel{\circ}{C}$} \\
\hline & $\begin{array}{l}\mathrm{H}_{\text {crit }} \\
(\mathrm{mm})\end{array}$ & $D_{\text {crit }}$ & $\begin{array}{c}H_{\text {crit }} \\
(\mathrm{mm})\end{array}$ & $D_{\text {crit }}$ & $\begin{array}{l}\mathrm{H}_{\text {crit }} \\
(\mathrm{mm})\end{array}$ & $D_{\text {crit }}$ & $\begin{array}{c}\mathrm{H}_{\text {crit }} \\
(\mathrm{mm})\end{array}$ & $D_{\text {crit }}$ & $\begin{array}{l}\mathrm{H}_{\text {crit }} \\
(\mathrm{mm})\end{array}$ & $D_{\text {crit }}$ & $\begin{array}{l}\mathrm{H}_{\text {cirt }} \\
(\mathrm{mm})\end{array}$ & $D_{\text {crit }}$ \\
\hline N0 & 5.84 & 0.529 & 5.29 & 0.567 & 4.38 & 0.633 & 4.43 & 0.629 & 3.17 & 0.72 & $\begin{array}{ll}- \\
-\end{array}$ & - \\
\hline N2 & 10.17 & 0.261 & 10.16 & 0.262 & 8.11 & 0.381 & 5.26 & 0.57 & 3.16 & 0.72 & & - \\
\hline N4 & 10.18 & 0.26 & 10.17 & 0.261 & 8.12 & 0.38 & 4.4 & 0.631 & 3.18 & 0.72 & - & $\begin{array}{ll}- & -1 \\
-1\end{array}$ \\
\hline
\end{tabular}

Figure 18 shows that the absolute critical damage curves for N2 and N4 are very similar and therefore, it may be concluded that there is no difference between either of them, in terms of absolute critical damage.

If the damage results obtained in this research work are compared with those from the parts shown in Figure 16, it may be observed that a temperature of 150 ${ }^{\circ} \mathrm{C}$ is required in order to forge the NO connecting rod and a temperature higher than $200 \stackrel{\circ}{\circ}$ in the case of $\mathrm{N} 2$ and $\mathrm{N} 4$. 


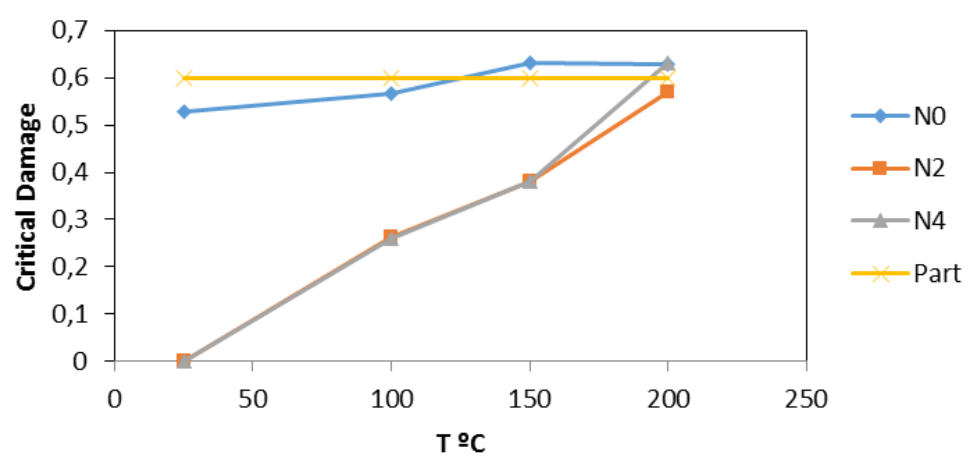

Figure 18. Absolute critical damage evolution for $A A 3103$ as a function of temperature

\section{Conclusions}

The evolution of damage values for a specimen with a novel geometry based on that previously proposed by Gouveia et al. has been studied by finite volume simulations in the form of an isothermal compression between plane-shape dies. Not only the damage evolution using the Cockroft-Latham's criterion is dealt with but also its distribution along the specimen with the aim of concentrating the maximum damage value at a specific zone which is easy to visualise.

Moreover, an experimental study has been carried out in order to evaluate the appearance of cracks in the case of the isothermal compression between planeshape dies for three different aluminium alloys: AA5754, AA5083 and AA3103. Through this present study, crack appearance is managed to be predicted as a function of the final height to within an accuracy of $0.5 \mathrm{~mm}$. With the results obtained in the finite volume simulations, the absolute critical damage value is obtained at each temperature value.

It has been observed that by comparing these results with those obtained in earlier studies on the forging of mechanical components it is possible to predict the formation of cracks before the material is forged.

The results obtained in the case of AA5754 show that the temperature value at which no cracks appear for N0 and N2 with flash treatment states is $200^{\circ} \mathrm{C}$. On the contrary, for $\mathrm{N} 2$ and $\mathrm{N} 4$ states, it is necessary to reach $250{ }^{\circ} \mathrm{C}$ and $300{ }^{\circ} \mathrm{C}$, respectively, for the material to have no cracks. That is to say, by means of the ECAP process, combined with a recovery heat treatment (in this case, N2 with flash treatment), it is possible to achieve damage behaviour similar to the N0 state alloy but with an increase in microhardness of around $10 \%$. 
With respect to AA5083, cracks in the N0 specimens appear up to temperature values of $250 \stackrel{\circ}{\circ}$. Moreover, in order to obtain a N2 specimen with no cracks, it is necessary to reach a temperature value of $300 \stackrel{\circ}{ } \mathrm{C}$. Finally, regarding AA3103, it is found that the temperature value at which no cracks appear is $250{ }^{\circ} \mathrm{C}$, regardless of the starting state for the aluminium alloy.

The results obtained by experimental tests in the case of the forging of two mechanical components (a ring and a connecting rod) agree well with those obtained by finite element simulations, where a very high correlation level is observed in relation to damage in both cases.

\section{Acknowledgements}

The authors of this present research work acknowledge the support given by the Ministry of Economy and Competitiveness through the Research Project Research Project DPI2013-41954-P.

\section{References}

[1] Bouchard, P.O.; Bourgeon, L.; Fayolle, S.; Mocellin, K., An enhanced Lemaitre model formulation for materials processing damage computation, International Journal of Material Forming, Vol. 4 (3), 2011, pp. 299-315.

[2] Lemaitre, J.; Desmorat, R.; Sauzay, M., Anisotropic damage law of evolution, European Journal of Mechanics - A/Solids, Vol. 19 (2), 2000, pp. 187208.

[3] Shen, Y.; Garnier, J.; Allais, L.; Crepin, J.; Ancelet, O.; Hiver, J.-M., Experimental and numerical characterization of anisotropic damage evolution of forged Al6061-T6 alloy, Procedia Engineering, Vol. 10, 2011, pp. 3429-3434.

[4] Gouveia, B.P.P.A.; Rodrigues, J.M.C.; Martins, P.A.F., Fracture predicting in bulk metal forming, International Journal of Mechanical Sciences, Vol. 38 (4), 1996, pp. 361-372.

[5] Puertas, I.; Luis Pérez, C.J.; Salcedo, D.; León, J.; Fuertes, J.P.; Luri, R., Design and mechanical property analysis of AA1050 turbine blades manufactured by equal channel angular extrusion and isothermal forging, Materials and Design, Vol. 52, 2013, pp. 774-784.

[6] Luis Pérez, C.J.; Salcedo Pérez, D.; Puertas Arbizu, I., Design and mechanical property analysis of ultrafine grained gears from AA5083 previously 
processed by equal channel angular pressing and isothermal forging, Materials and Design, Vol. 63, 2014, pp. 126-135.

[7] Cockcroft, M.G.; Latham, D.J., Ductility and the workability of metals, Journal of the Institute of Metals, Vol. 96, 1968, 33-39.

[8] Liu, P.F.; Zheng, J.Y., Recent developments on damage modeling and finite element analysis for composite laminates: A review, Materials and Design, Vol. 31, 2010, pp. 3825-3834.

[9] Luri, R.; Luis Pérez, C.J.; Salcedo, D.; Puertas, I.; León, J.; Pérez, I.; Fuertes, J.P., Evolution of damage in AA-5083 processed by equal channel angular extrusion using different die geometries, Journal of Materials Processing Technology, Vol. 211 (1), 2011, pp. 48-56.

[10] Comaneci, R.; Zaharia, L.; Chelariu, R., Damaging prediction of difficult-towork aluminum alloys during equal channel angular pressing, Journal of Materials Engineering and Performance, Vol. 21 (3), 2012, pp. 287-297.

[11] Figueiredo, R.B.; Cetlin, P.R.; Langdon, T.G., The evolution of damage in perfect-plastic and strain hardening materials processed by equal-channel angular pressing, Materials Science and Engineering: A, Vol. 518 (1-2), 2009, pp. 124-131.

[12] Katani, S.; Madadi, F.; Atapour, M.; Ziaei Rad, S., Micromechanical modelling of damage behaviour of Ti-6Al-4V, Materials and Design, Vol. 49, 2013, pp. 1016-1021.

[13] Costa Mattos, H.S.; Minak, G.; Di Gioacchino, F.; Soldà, A., Modeling the superplastic behavior of $\mathrm{Mg}$ alloy sheets under tension using a continuum damage theory, Materials and Design, Vol. 30 (5), 2009, pp. 1674-1679.

[14] Pepel, V.; Žerovnik, A.; Trajkovski, J.; Prebil, I., Comparison of three different methods for determination of damage in solid materials, Materials and Design, Vol. 56, 2014, pp. 872-877.

[15] Shang, D.-G., Measurement of fatigue damage based on the natural frequency for spot-welded joints, Materials and Design, Vol. 30 (4), 2009, pp. 1008-1013.

[16] C. J. Luis, D. Salcedo, J. León, I. Puertas, J. P. Fuertes, and R. Luri, "Manufacturing of Nanostructured Rings from Previously ECAE-Processed AA5083 Alloy by Isothermal Forging," Journal of Nanomaterials, vol. 2013, Article ID 613102, 14 pages, 2013. 